\title{
By what standard? Speech-related conduct issues in globalised sports
}

\author{
Myles Bayliss $^{1}$ (D)
}

Accepted: 23 December 2021 / Published online: 28 February 2022

(c) Crown 2022

\begin{abstract}
The ban of Uruguayan footballer Edinson Cavani for a post on his Instagram account has been highly controversial. Opinions as to the appropriateness of the ban and associated stance taken by the Football Association have been divided. On one side, groups such as anti-racism campaigners have argued that the ban is justified citing a need to promote a greater understanding of acceptable language and behaviour among international athletes. On the other hand, many Spanish speakers have argued that the Associations' actions are inconsistent with their stance on inclusivity and understanding, arguing that they failed to consider the cultural and linguistic characteristics unique to South America. This raises an important question for globalised sports: how should words and speech be judged in an international context?
\end{abstract}

Keywords Football $\cdot$ Language $\cdot$ Discrimination

\section{Introduction}

In late December 2020, Uruguayan footballer Edinson Cavani received a three-game suspension and a $£ 100,000$ fine for a breach of Football Association Rule E3(1). Cavani's breach related to a post on his personal Instagram account wherein the player thanked a childhood friend by posting the phrase "Gracias Negrito". Issue was taken with the term "negrito" which the Football Association ("FA") considered to be an aggravated breach of Rule E3, arguing the post was an aggravated breach of the Rule due to the term's implicit connection with race or ethnic origin. While Cavani would admit the allegation against him and accept the sanction, opinions in respect of the validity of the FA's concerns have been divided.

Critics of the ban variously argue that Cavani's post did not contain a racial connotation, rather the term negrito is argued to typically be used in Spanish speaking countries like Uruguay as a term of endearment rather than a racial slur. Supporters of this stance have included the Uruguayan Football Players' Association

\footnotetext{
${ }^{1}$ Roughly translating to "Little Black Man". In full Cavani's post may be translated to something resembling "Thanks little black man".
}

Myles Bayliss: LLB, B.Comm, Solicitor of the Supreme Court of Queensland and High Court of Australia.

Myles Bayliss

myles.bayliss@griffithuni.edu.au

1 Griffith University, Brisbane, Australia
("AFU"), The Uruguayan Academy of Letters, and the South American Football Confederation ("CONMEBOL") have all expressed support for Cavani, arguing that the FA has not properly taken into consideration broader cultural characteristics - particularly the use of certain terms in everyday speech — when choosing to take disciplinary action against Cavani. ${ }^{2}$ Supporters of the ban such as anti-racism campaigners have argued that the acceptability of the term in South America is irrelevant instead contending the relevant is what is considered acceptable speech and behaviour in England, the jurisdiction in which Cavani presently ply's his trade. Others also argue that the term has implicit racial or ethnicity focused implications despite its common use in Spanish vernacular rendering the term unacceptable.

The divide has generated significant discussion as to whether Cavini's ban is consistent with the ideals of promoting cross-racial and cultural understanding and acceptance. For example, the anti-racism organisation Kick It Out made the following post on its Twitter account on 1 January $2021:^{3}$

\footnotetext{
2 Asociación Uruguaya de Fútbol, 'Communicade de la AUF 4.1.2021' (Media Release, 4 January 2021) https://www.auf.org. uy/comunicado-de-la-auf-4-1-2021/; Academia Nacional de Letras, 'Ante la sancion a Edinson Cavani' (Media Release, 31 December 2020) http://www.academiadeletras.gub.uy/innovaportal/v/124868/ 46/mecweb/ante-la-sancion-a-edinson-cavani? parentid=123710; CONMEBOL, La CONMEBOL expresa su solidaridad con Edinson Cavani https://www.conmebol.com/es/la-conmebol-expresa-su-solid aridad-con-edinson-cavani.

3 @ kickitout, (Twitter, 1 January 2021, 1:23 AM) https://twitter.com/ kickitout/status/1344665531425705989.
} 
We believe it would be helpful for overseas players coming to play in England, to have consistent education on language or behaviour that may be unacceptable in this country. That would help prevent situations, like this with Cavani and others, from reoccurring in the future.

Various replies to the Tweet argued that the organisation was being hypocritical of their mission by supporting the ban, stating the ban was discriminatory of Latin-heritage players and echoed historical imperialistic or colonist practices of imposing language and culture upon indigenous peoples. While supporters of the ban may argue that this criticism is essentially an absurdist characterisation of antiracist positions and arguments, there prima facie appears to be a point as it appears somewhat inconsistent to espouse an ideal of cultural understanding while simultaneously punishing someone for otherwise acceptable behaviour in their culture of origin due to it being unacceptable when viewed through a different cultural lens.

Against this background a very valid question is raised: how should foreign words and speech be judged and what standard should be applied. This is a pertinent question in globalised sports with diverse player bases such as football and requires a fine balancing of interests. While there is likely no absolutely correct answer or approach to assessing these kinds of matters there is room to review and rebalance the process to maximise its utility. To this end, this article will examine Rule E3 against the Cavani case as well as other key disciplinary cases on similar topics.

\section{The Cavani case}

The Cavani case is a "hard case". ${ }^{4}$ While an established rule exists, the rule and its surrounding policy appears to offer conflicting guidance, ${ }^{5}$ placing the true and correct or "best" interpretation in doubt. While the correctness of the ban decision generally seems to rest on the individual's personal convictions, it must be understood why the case has been so divisive. To this end, this section will review the written reasons relating to Cavani's ban followed by a substantive examination of Rule E3 and key cases relating to the rule.

\subsection{FA v Cavani}

The Cavani matter was assessed on 31 December 2020 in the absence of the parties by the FA Regulatory Commission. As Cavani admitted the allegation, the Commission was appointed to determine the appropriate penalty, namely,

\footnotetext{
${ }^{4}$ Dworkin (1978, p. 81), Twining and Miers (1991).

${ }^{5}$ Hart (1976, p. 547).
}

whether it was appropriate to depart from the Standard Minimum Penalty for offences of this kind. ${ }^{6}$

The breach of Rule E3 was stated to be Cavani's public response to an Instagram post from a close childhood friend congratulating Cavani on a recent performance. The congratulatory post included a picture of Cavani performing a goal celebration captioned with the words "Asi te quiero Matadorrr!!!!!" ("I love you like a bull fighter"). Cavani responded publicly with a handshake emoji and the words "Gracias negrito". 7

The FA did not seek to establish that Cavani deliberately acted with racist or offensive intent in making the comment, rather the issue was whether a reasonable observer with no understanding of South American cultural norms in respect of the use of the word "negrito" and no knowledge of the relationship of the parties involved would consider the word "negrito" a breach of Rule E3(2). ${ }^{8}$ As put by the Commission:

... when translated in a foreseeable way, The FA submitted that a follower of English Premier League football would have understandably concluded that the words used were racially offensive. ${ }^{9}$

While Cavani accepted that his words could have been construed as offensive, it was submitted in mitigation that he could not have reasonably known that his words would be considered offensive. ${ }^{10}$ In mitigation, Cavani submitted that the reply was not intended to be offensive or in reference to race or ethnicity, it was simply the childhood nickname of his friend.

The Commission accepted the following factual circumstances: Cavani was born in Uruguay, spoke little to no English and had not previously lived in a country with English as the primary language; Cavani's friend is a man of Caucasian appearance; the life-long nickname of the friend was "negrito", usage of the nickname was commonplace among the friend group, the nickname was not used to cause offence. ${ }^{11}$ The Commission also noted the expert evidence of Professor David Wood, a Latin America studies expert, who stated that the word would commonly be used to refer to a male of colour but could also be used in a friendly context with no racial, insulting or offensive context. Professor Wood did, however, note that native English speakers unfamiliar with South American culture would likely take offence to the words used. ${ }^{12}$

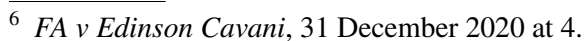

7 Ibid, 7-8.

8 Ibid, 13-14.

9 Ibid, 15.

${ }^{10}$ Ibid, 22.

11 Ibid, 9.

12 Ibid, 10.
} 
The Commission was ultimately satisfied that Cavani could not have reasonably known that the word "negrito" could have cause offence. In reaching, the conclusion the Commission had regard to the fact that Cavani had only been residing in England for approximately two months as well as his English skills and previous countries of residence. Accordingly, the Commission was satisfied that it was not proper to infer Cavani had been sufficiently exposed to the language and culture of England to understand that the word was unquestionably offensive in England regardless of the acceptability in his native language. ${ }^{13}$ The Commission was, however, surprised that Cavani had not received any education or media training to better understand the cultural differences between his native and current place of residence.

The Commission therefore determined that departing from the Standard Minimum would be appropriate and that any reasonable observer with a full knowledge of the background and context of the case would perceive the departure as consistent with balancing the interest of addressing discrimination while also reflecting appropriately upon the culpability of Cavani. ${ }^{14}$

\subsection{Rule E3}

Rule E3 as outlined in the FA Handbook 2020-2021 Season edition relevantly states:

E3.1 A Participant shall at all times act in the best interests of the game and shall not act in any manner which is improper or brings the game into disrepute or use any one, or a combination of, violent conduct, serious foul play, threatening, abusive, indecent or insulting words or behaviour.

E3.2 A breach of Rule E3.1 is an "Aggravated Breach" where it includes a reference, whether express or implied, to any one or more of the following :- ethnic origin, colour, race, nationality, religion or belief, gender, gender reassignment, sexual orientation or disability.

...

A key consideration of Rule E3 is that the prohibition is expressed in terms that do not necessarily require any person to be offended or insulted, rather the bar is simply bringing the game into disrepute. The prohibition being phrased in more general terms is beneficial in respect of flexibly protecting a wider range of the sports' interests by having a broader scope of potential application.

Conduct alleged to breach Rule E3 is to be assessed objectively. In a case involving another Uruguayan footballer,

\footnotetext{
13 Ibid, 27.

14 Ibid, 30.
}

Luis Suarez, ${ }^{15}$ the Commission explained the approach as follows:

"57. In our judgment, the test for breach of Rule E3(1) is objective. The question is simply whether the words or behaviour are abusive or insulting. This is a matter for the Commission to decide, having regard to all the relevant facts and circumstances of the case. It is not necessary that the alleged offender intends his words or behaviour to be abusive or insulting in order for him to breach Rule E3(1). There are a number of reasons which lead us to this conclusion.

58. First, the starting-point is the natural and ordinary meaning of the words of Rule E3(1). Focussing on the words applicable to this case, Rule E3(1) states that a Participant shall not use abusive or insulting words or behaviour. The words are not complicated. The words of the Rule suggest to us that we should ask ourselves: do we consider the words or behaviour to be abusive or insulting? We have been entrusted with the task of answering that question. That the question may be difficult to answer in particular cases does not alter the fact that it is a straightforward question, uncomplicated by legal technicalities.

....

71. We do accept the broad thrust of Mr McCormick's alternative submission however. In applying the objective test and asking ourselves whether, in our assessment, the words or behaviour are abusive or insulting, it is necessary to view the matter in context, taking account of all relevant fact and circumstances. This would include, amongst other things, the fact that many overseas players play their football in England, and many languages are spoken by the players."

In theory, the approach as outlined by the Suarez iteration of the Commission would tend to support the arguments of those opposed to the ban of Cavani, that words need to be viewed objectively and in context. This did happen to a degree where the Commission considered the relationship between Cavani and his friend and the expert evidence of Professor Wood; however, as neither Cavani or his club contested the matter, the evidence was not substantively tested. Had the matter proceeded to a hearing perhaps the objective test would have received greater scrutiny as in the Suarez case.

\subsection{FA v Suarez}

The Suarez case is highly relevant as it concerned the use of the Spanish word "Negro" in an on-field incident between Uruguayan player Luis Suarez and French player Patrice Evra

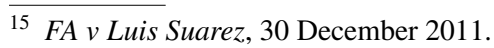


who is of West African descent. Both players gave different accounts of the incident with Evra claiming that Suarez had used the word in an abusive context which was denied by Suarez who claimed he only used the phrase "Por que, Negro" which was intended to be conciliatory and friendly, consistent with typical usage in Uruguay. ${ }^{16}$ Suarez claimed that where he came from it was normal to refer to people by reference to what they look like. ${ }^{17}$ Suarez did concede that he understood this may not be acceptable in English. ${ }^{18}$

Again, the Commission would consider expert linguistic and cultural evidence of the word "Negro" in Latin America, accepting that the term is generally ambiguous in all Spanish speaking countries and dialects and is not always used in offensive fashion. ${ }^{19}$ It was accepted that it was common to refer to people by visual traits such as hair colour or skin tone which could be done without malice. It was, however, noted that it was not uncommon for the term to be used as a pejorative in Uruguay and Latin America. ${ }^{20}$ It was also noted that Evra may have misunderstood he meaning of "Negro" in Spanish due to his personal knowledge of the Italian language where "Negro" is a racial slur. ${ }^{21}$ The Commission's decision would not be affected by this however.

Ultimately the Commission would find the charge against Suarez proved making the decision based upon the circumstances of the on-field incident rather than the word itself. The Commission concluded that the exchange between the player was based in animosity and while Evra started the confrontation, the actions of Suarez were not consistent with the assertions of attempted conciliation or de-escalation..$^{22}$ The Commission deemed Suarez to be an inconsistent witness thereby preferring the evidence of Evra as to the sequence of events. Consistent with the expert evidence, it was deemed that the words would have carried an offensive element in Uruguay or other regions of Latin America ${ }^{23}$ thereby satisfying the insulting criteria of Rule E3(1) and the aggravating element of (2). ${ }^{24}$

\footnotetext{
$\overline{16}$ Ibid, 5-6. Note that Evra is not fluent in Spanish but can easily converse in the language: at 87.

17 Ibid, 256.

18 Ibid, 254.

19 Ibid, 167-176.

20 Ibid, 351.

${ }^{21}$ Ibid, 272

22 Ibid, 264 and 356-357.

23 Ibid, 391.

${ }^{24}$ See also the similar case of FA v John Terry, 24 September 2012 which also concerned a confrontation between players and an aggressive reference to skin colour but in English. The inquiry found Terry guilty of racial abuse at the civil standard after failing at the criminal standard: $R$ v Terry (13 July 2012).
}

\subsection{FA v Anelka}

An additional relevant case is $F A v$ Nicolas Anelka ${ }^{25}$ in which the Commission was required to determine whether a gesture known in French as "le quenelle" was in breach of Rule E3. The gesture was performed by French player Nicolas Anelka after scoring a goal, the gesture was not directed at anyone but was claimed to be performed for the creator of the gesture who was a friend of the player. ${ }^{26}$ The Commission would conclude that the charge was proved owing to a clear link between the gesture and the anti-Semitic sentiments of its creator that would be clearly understood by a French audience. ${ }^{27}$

The Commission considered expert evidence as to the broader cultural meaning and understanding of the gesture. The gesture was first performed in 2005 by well-known French comedian and political activist Dieudonné M'bala. It was accepted that the first sketch in which the gesture was performed was not directed at any race or culture, but did have lewd implications. ${ }^{28}$ The gesture was noted to have at least initially been taken up in mainstream popular culture as something of an "up yours" gesture and is often posted on social media without necessarily having negative connotations. ${ }^{29}$ The gesture progressively gained more pointed political connotations, mainly due to the association with its creator who since the early 2000's had come to increasingly hold public anti-Semitic views, even to the extent of being convicted for anti-Semitism offences under French law on multiple occasions. ${ }^{30}$

Against the above context, it was concluded that at least initially the gesture was conceived as a lewd gesture for use in a comedy show which itself would have been sufficient to breach Rule E3(1). ${ }^{31}$ It was accepted that there was an inextricable link between the gesture and its creator, as the creator was a prolific public figure that maintained a close association with the gesture. Accordingly, it was concluded that while the gesture may mean noting to the uninitiated English audience it would be understood by a majority of people in France to have anti-Semitic connotations. ${ }^{32}$

\footnotetext{
2525 February 2014. Cf FA v Wayne Hennessey, 12 April 2019 at 39 in which the Commission rejected an assertion that the player had performed a "Nazi salute" while in a restaurant as there was no logical reason for having done so (either to cause offence to or amusement for any person in the room).

${ }^{26}$ Ibid, 67.

27 Ibid, 94.

${ }^{28}$ Ibid, 26.

${ }^{29}$ Ibid, 30, 51-52 and 90.

${ }^{30}$ Ibid, 31 and 85-87.

31 Ibid, 82 and 96

${ }^{32}$ Ibid, 48 and 95.
} 


\section{What did you say?}

The above cases demonstrate the tensions present when judging non-English languages against the cultural and linguistic standards of England and the English language. In Suarez, the Commission noted at paragraph 174 that in Latin America there are a variety of descriptive terms that may seem odd or offensive to the unfamiliar European ear. Similarly in the Anelka case, the determination revolved around a gesture that would generally not be understood by English fans with no knowledge or appreciation for French politics or popular culture. This is not to argue that it was inappropriate to punish either player or that either decision was wrong, this is simply to highlight the difficulties associated with properly judging a word or action that exists outside of the typical mainstream or majority culture.

Outside of sport a similar situation arose when the company Microsoft utilised South Korean girl group 2NE1's song "I Am the Best" (내가 제일 잘 나 가) as part of a marketing campaign. ${ }^{33}$ The Microsoft video advert featured a censored version of the song, not because of the inclusion of profanity but due to the repeated use of the words 내 가 (pronounced "naega") and 네 가 (pronounced "neega") which are the Korean word-equivalents for "I" and "You", respectively; the song lyrics have the singers frequently repeat both the titular phrase and the individual words. Those unfamiliar with the Korean language would likely mishear the wordsas well as an alternative form of the word for "You" (L) 가 pronounced "niga")—due to the auditory similarity with English language racial slurs. This purportedly also led to some American radio stations censoring parts of the song, either due to mishearing/misunderstanding, or out of caution. ${ }^{34}$ This has purportedly occurred again more recently with another South Korean band, boy-band BTS and their song "Fake Love". ${ }^{35}$ This has sparked concern among fans of Kpop and Korean speakers that the censoring of such words may lead to a misrepresentation of Korean media and language. With the increasing global popularity of Korean media, particularly Kpop, and the associated attention this brings to ethnic Koreans and Korean speakers, this is a valid concern.

\footnotetext{
33 Sohn Ji-Young, Microsoft Features 2NE1 Song in New Ad, The Korea Herald (online) (13 August 2014) http://www.koreaherald. com/view.php?ud=20140813000863.

${ }^{34}$ Staff Writer, Boston Radio Station Censors 2NE1's 'I Am the Best' For Misheard Lyrics; Fan Uploads a Video Expressing Her Reaction on the Censorship, Venture Capitalist Post (online) (4 November 2014) https://www.vcpost.com/articles/31029/20141104/ radio-station-censors-2ne1-i-am-the-best-for-misheard-lyrics-fanuploads-video-reaction.htm.

35 Emma Kelly, Here's Why BTS's Fake Love is Being Censored on US Radio, Metro (22 May 2018) https://metro.co.uk/2018/05/22/btssfake-love-censored-us-radio-7568200/.
}

As seen in the written reasons for the Cavani case the issue was not necessarily the actual meaning of the word but the perception of the word by observers. Importantly these observers do not need to be aware of or knowledgeable about the meaning or usage of the word in its native context, it is sufficient that it may be "reasonably" perceiveable as offensive. While the reasonable person test is standard legal orthodoxy as an objective assessment of a set of facts, the test may hold limited egalitarian promise where the objective reasonableness standard is rigidly based on socially-dominant norms. ${ }^{36}$ The Commission did appear to understand this in the Anelka case, focusing their line of inquiry to whether French observers or other informed parties would consider the gesture offensive before apply Rule E3. Curiously however this appeared to be departed from in the Cavani case.

The prima facie justification for Cavani's ban is that the player admitted the breach rather than contesting. This notwithstanding, in the assessment of the penalty the word was assessed against a standard based on a reasonable observer with "... with no understanding of South American cultural norms in respect of the use of the word "negrito", and with no understanding of the relationship between the Player and his close friend ...". While it can be argued that previous Commission decisions are not rigidly binding, this assessment seems illogical considering the case also concerned a substantive examination of the word "negrito" and its usage in Latin America. Should the applicable standard be the unknowing "reasonable" person this examination was wholly unnecessary and irrelevant.

Inarguably this can create a problematic scenario that is at odds with an overarching policy of cultural understanding and harmony. Simply because a "foreign" word may evoke feelings or perceptions of offence is not a good justification for reactive discipline $;{ }^{37}$ such a standard may result in illinformed responses leading to outcomes that may undermine confidence in the disciplinary system and foster discontent among non-English speaking or ESL players and fans.

\footnotetext{
36 Moran (2003, p. 275).

37 See the speech of Baroness Hale in $R$ (Begum) $v$ Headteacher and Governors of Denbigh High School [2007] 1 AC 100, para 96-97. While her Ladyship would join with the remainder of the House of Lords in ruling that a school had acted proportionately in refusing to allow a 16-year-old student to wear a jilab in place of permitted uniform (including religious alternatives) it was made clear that simply because offence or negative assumptions could surround the garment, that by itself was not a good or sufficient reason to prevent the student wearing it.
} 


\section{Mind your language: how should we judge words?}

The pertinent issue is by what standard should these purported conduct breaches by judged. As noted by the Commission in Suarez, their role is to determine whether a word is appropriate in England. ${ }^{38}$ While it is legal orthodoxy to impose the norms and standards of the jurisdiction upon those subject to the jurisdiction, ${ }^{39}$ as stated in the preceding section this may lead to problematic outcomes that are not consistent with the ideals and objectives of multiculturalism. The Commission's statement as to their role is consistent with the often-held assumption that the best method for promoting equality is to impose a uniform set of rules to create identical choice sets and equal opportunities. ${ }^{40}$ This approach is however argued to ignore pre-existing disparities and circumstances of non-majority groups. ${ }^{41}$ Even when equal opportunity policies and diversity efforts are in place, feelings of exclusion or discrimination may still be fostered among athletes where the institution is premised upon socially dominant ideals or standards. ${ }^{42}$ As Malcolm notes, sporting equal opportunity policies are often based on an empathy with the perspective of the 'white-established', as opposed to the 'minority ethnic-outsider'. ${ }^{43}$

Increasingly courts and tribunals are rejecting the hardline policy of treating everything as 'like' by recognising that not only may the 'unlike' have to be treated differently in order to further equality. ${ }^{44} \mathrm{Against}$ this context, the norm may have to be reconsidered to meet the needs of an increasingly multicultural world. Multiculturalism is characterised by the integration of characteristics and culture in an atmosphere of mutual tolerance, not a demand for assimilation. ${ }^{45}$ Accordingly, an objective test such as the reasonable person test should theoretically be sufficient for the purpose of assessing speech and conduct across cultural and linguistic borders due to the supposed dispassionate observation of the factual scenario. As noted, however this test may still fail as the reasonableness standard may be influenced by notions of what is

\footnotetext{
38 Suarez n 15 at 202 and 389.

39 Notwithstanding any potential mitigating considerations relating to culture or familiarity that may arise.

40 See for example the arguments in Barry (2001).

${ }^{41}$ Shachar (2001, p. 279).

42 MacDonald and Ugra (1998, pp. 17 and 32-34).

43 Malcolm (2002, p 313).

44 Thlimmenos v Greece (2001) 31 EHRR 411 at [44]; Vertovec and Wessendorf (2009, p. 14).

45 Poulter (1987, p. 591), McColgan (2014, p. 188).
}

the norm by the socially dominant culture. ${ }^{46}$ This appears to have been the case in Cavani where the Commission seems to have favoured the idea that the reasonable observer of the English Premier League has no understanding of the Spanish language or linguistic customs in Latin America.

While perhaps reasonable to assume that the average English speaker residing in England may not have such specific knowledge, it is still questionable why the uniformed reasonable person is preferred over the informed/knowledgeable reasonable person. While personifying the reasonable person beyond simply being a dispassionate observer aware of all circumstances does present some dangers-namely in undermining credible objectiveness ${ }^{47}$ - the alternative of the uninformed reasonable person would similarly undermine the credibility of the sport's disciplinary system, something repeatedly stated by internet commentators such as those replying to the Kick It Out tweet. This would also appear to be at odds with the ideals adopted by the administration through the implementation of anti-discrimination and diversity policies. Although there is a strong argument that eliminating all potential forms of discrimination no matter the scope or intention should take primacy, this hard-line stance may in itself be inadvertently discriminatory by considering words in a vacuum based on supposition rather than in actual context.

A further exaggerating issue may be Rule E3 itself as it is merely premised upon the idea of lowering the broader reputation of the game i.e., causing a negative impact on the game's image. Out of necessity these rules are generally broad to avoid negative conduct falling outside the scope. The corollary of this broadness however results in imprecise criteria being applied which may result in different decision-makers reaching differing conclusions even when rationally assessing the facts and circumstances of the case. ${ }^{48}$ This is compounded by the fact that the concept of 'best interests' of the game are generally foreign to a court or tribunal, thereby requiring some expert knowledge in the application of related rules. ${ }^{49}$

The obvious downfall of this approach is that the application of such rules is therefore largely subjective resulting in sometimes unclear expectations of the standards that must be upheld by both players and administrators. ${ }^{50}$ The

\footnotetext{
46 Thus running counter to the moral imperative to make equal judgments of individuals who behave identically: Dworkin (2002), Rawls (2001).

47 King (2017, p. 733).

${ }^{48} R$ v Monopolies \& Mergers Commission; Ex parte South Yorkshire Transport Ltd [1993] 1 WLR 23, 32 per Lord Mustill referred to in Australian Football League v Carlton Football Club [1998] 2 VR 546 at 559 per Tadgell JA applied in Old Melburnians Football Club Incorporated v Victorian Amateur Football Association [2001] VSC 34 [42].

49 Charles 0 Finley \& Co v Kuhn 569 F 2d 527 (7th Cir 1978) at 537.

${ }^{50}$ Paterson (2009, p. 136).
} 
resultant uncertainty causes inconsistent application of the rules which itself undermines the legitimacy and integrity of the sport. ${ }^{51}$ To address the deficiencies in the orthodox approach, Kosla proposes a framework based on the common law principles of equity and defamation. ${ }^{52}$ Under this framework 'conduct unbecoming' should amount to actions that are 'so outrageous that the sport itself is subjected to public ridicule'. The issue with this standard however is that it is still largely subjective and does not account for the fact that players may be disciplined unfairly simply due to initial adverse publicity or reactionary sentiment from uninformed observers. ${ }^{53}$ While it can be said that players are simply asked to abide by existing laws and standards-as is any other person - the heightened commerciality of sports and associated public exposure places players in a position wherein they receive heightened negative publicity for minor or even non-offences that would harm their employer more so than in a traditional employment relationship. ${ }^{54}$

To address the persistent uncertainty issues, Paterson proposes the inclusion of references clarifying unbecoming conduct that are consistent with existing legal framework regulating out of hours conduct of employees. ${ }^{55}$ As the fields of sports and employment law are highly similar, if not identical at least in respect of the treatment of 'out of hours' conduct, ${ }^{56}$ existing legal frameworks should be readily transmutable. Paterson's proposal also includes reference to a new reasonable person test that considers what the reasonable person would consider likely to harm the interests of a sports league or its member clubs. This test would consider whether the reasonable person considers that the athlete's behaviour would:

- Place revenues in jeopardy; or

- Lead to fewer participants at the grass roots level or discourage juniors from continuing to participate in the sport.

Paterson readily admits that under this standard there is still a high likelihood that athletes could still be punished on the basis of initial adverse publicity, however the improvement upon the standard consideration is that it includes noncommercial considerations of the impact of the conduct. This is pertinent for considering speech or imagery related breaches such as those committed by Cavani and Suarez. Under this standard the Commission could consider the

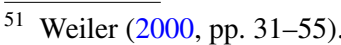

52 Kosla (2001, p. 670-674).

53 Paterson (2009, p. 138).

${ }^{54}$ Ibid, p. 142.

55 Ibid, p 138.

56 Goodwin (2005, p. 248).
}

perceptions of the groups most affected by alleged conduct which would more readily incorporate non-White voices into the process rather than being premised purely on the standards or perceptions of the socially dominant culture.

As found by MacDonald and Ugra, ${ }^{57}$ non-White amateur athletes often harboured feelings of distrust or indifference to the administration of their sporting league, particularly the disciplinary system due to the perceived predominance of White opinion over their own. This would lead to perceptions that the system was biased against them or that the White majority did not care about issues faced by non-White athletes. On this basis modifying the scope of the inquiry to expressly consider these persons may alleviate these negative perceptions of the sport and its administration.

While under this standard Cavani may very well still have received a suspension and it is very likely that incensed internet commentators would lament the fallibility of the disciplinary system, this modification would add another layer of transparency for those that care to properly look as well as taking greater steps to reconcile the administration with its goal of incorporating diversity across all aspects of the sport.

\section{Conclusion}

In an increasingly globalised world, it is important that institutions are open and accepting of people of diverse circumstances. To this end it is necessary to have policies and procedures in place to protect individuals from prejudice based on their immutable characteristics. A key mission of many equitable organisations is the promotion of understanding and knowledge of other cultures. Despite the efforts of many organisations, the actual effect of these policies may not always match with the overarching goals. A key area that this occurs is the disciplinary process which was highlighted by a recent Football Association case against Premier League player Edinson Cavani. The case against Cavani was unqiue and concerned a judgment of the meaning and implication of non-English words using English language and cultural standards. Perceptions of the outcome of the process have been starkly divided with many commentators arguing that the disciplinary Commission failed to properly consider the cultural and linguistic nuances of words in Cavani's Instagram post.

The case of Cavani and several other footballers involving non-English words or gestures does give the opportunity to pause and reconsider the standards involved in disciplinary inquiry in increasingly globalised and diverse contexts. While there is an argument to be made about upholding

$\overline{57 \text { Above, n } 42 .}$ 
systemic integrity by treating the subjects of all cases the same, this hard-line stance may be more harmful than helpful as there is often significantly more nuance required to properly determine a case. A system overwhelmingly featuring culturally dominant standards and perceptions may foster negative feelings and perceptions among those not part of the dominant culture. To address these issues it may be beneficial to modify the approach taken to more expressly take into account non-majority voices and perceptions.

Funding Open Access funding enabled and organized by CAUL and its Member Institutions.

Open Access This article is licensed under a Creative Commons Attribution 4.0 International License, which permits use, sharing, adaptation, distribution and reproduction in any medium or format, as long as you give appropriate credit to the original author(s) and the source, provide a link to the Creative Commons licence, and indicate if changes were made. The images or other third party material in this article are included in the article's Creative Commons licence, unless indicated otherwise in a credit line to the material. If material is not included in the article's Creative Commons licence and your intended use is not permitted by statutory regulation or exceeds the permitted use, you will need to obtain permission directly from the copyright holder. To view a copy of this licence, visit http://creativecommons.org/licenses/by/4.0/.

\section{References}

Barry B (2001) Culture and inequality: an egalitarian critique of multiculturalism. Harvard University Press, Harvard

Dworkin R (1978) Taking rights seriously. Duckworth, London

Dworkin R (2002) Sovereign virtue: the theory and practice of equality. Harvard University Press, Harvard
Goodwin E (2005) Rules, referees and retribution: disciplining employee athletes in professional team sports. Austr J Labour Law 18:240

Hart H (1976) Law in the perspective of philosophy: 1776-1976. NYUL Rev 51:538

King M (2017) Against personifying the reasonable person. Crim Law Philos 11(4):725

Kosla M (2001) Disciplined for 'brining a sport into disrepute': a framework for judicial review. Melb Univ Law Rev 25(3):654

MacDonald I, Ugra S (1998) Anyone for cricket?: equal opportunities and changing cricket cultures in Essex and East London. Roehampton Institute and Centre for New Ethnicities Research.

Malcolm D (2002) Clean bowled? Cricket, racism and equal opportunities. J Ethnic Migration Stud 28(2):307-313

McColgan A (2014) Discrimination, equality and the law. Hart Publishing, London

Moran M (2003) Rethinking the reasonable person: an egalitarian reconstruction of the objective standard. Oxford University Press, Oxford

Paterson J (2009) Disciplining athletes for off-field indiscretions: a comparative review of the Australian Football league's personal conduct policies. Austr N Z Sports Law J 4(1):105

Poulter S (1987) Ethnic minority customs, English law and human rights. Int Compar Law Q 36:589

Rawls J (2001) Justice as fairness: a restatement. Harvard University Press, Harvard

Shachar A (2001) Two critiques of multiculturalism. Cardozo Law Rev 21:253

Twining W, Miers D (1991) How to do things with rules, 3rd edn. Weidenfeld and Nicolson, London

Vertovec S, Wessendorf S (2009) Assessing the backlash against multiculturalism in Europe. Working Paper 09-04, Max Planck Institute.

Weiler P (2000) Leveling the playing field: how the law can make sports better for fans. Harvard University Press, Harvard

Publisher's Note Springer Nature remains neutral with regard to jurisdictional claims in published maps and institutional affiliations. 